\title{
Radiographic signs for detection of femoroacetabular impingement and hip dysplasia should be carefully used in patients with osteoarthritis of the hip
}

Ingmar Ipach ${ }^{1,2^{*}}$, Ina-Christine Rondak ${ }^{3}$, Saskia Sachsenmaier ${ }^{1}$, Elisabeth Buck ${ }^{1}$, Roland Syha ${ }^{4}$ and Falk Mittag ${ }^{1}$

\begin{abstract}
Background: During the last years, terms like acetabular retroversion, excessive overcoverage, and abnormal head-neck-junction with the so called "pistol-grip-deformity" has been added to the classical description of hip dysplasia. These anatomical changes could lead to a femoroacetabular impingement (FAl). Both kinds of FAl has been indentified as a main reason for hip pain and progressive degenerative changes leading to early osteoarthritis of the hip. A lot of radiographic criteria on pelvic views have been established to detect classical dysplasia and FAl. The present study was initiated to assess the hypothesis that age and severity of osteoarthritis affect measurements of different radiographic parameters.
\end{abstract}

Methods: The pelvic radiographs of 1614 patients were measured for head-ratio, CE-angle, roof obliquity, extrusion-index, depth-to-width ratio, CCD-angle, sharp's angle. To evaluate the severity of osteoarthritis of the hip the classification by Kellgren and Lawrence was used. Associations between age and radiographic parameters or severity of osteoarthritis were assessed by Spearman's $(\rho)$ or Kendall's $(r)$ rank correlation coefficient, respectively.

Results: 366 (22.7\%) patients presented no sign of osteoarthritis, 367 (22.7\%) patients presented I osteoarthritis, 460 (28.5\%) patients presented II osteoarthritis, 307 (19\%) III osteoarthritis and 114 (7.1\%) IV osteoarthritis of the hip. The mean head-ratio of all patients was $1.13 \pm 0.26(0.76-2.40)$, the mean CE-angle $40.05^{\circ} \pm 10.13^{\circ}\left(0^{\circ}-70^{\circ}\right)$, the mean roof obliquity was $35.27^{\circ} \pm 4.96^{\circ}\left(10^{\circ}-55^{\circ}\right)$, the mean extrusion-index was $12.99 \pm 9.21(6.20-95.2)$, the mean depth-to-width ratio was $59.30 \pm 8.90(6.30-100)$, the mean CCD-angle was $127.68^{\circ} \pm 7.22^{\circ}\left(123^{\circ}-162^{\circ}\right)$ and the mean sharp's angle was $9.75^{\circ} \pm 5.40^{\circ}\left(1^{\circ}-34^{\circ}\right)$ There was a weak association between age and the severity of osteoarthritis of the hips (left: $r=0.291$; right: $r=0.275$; both $P<0.001$ ) with higher osteoarthritis levels observable for elderly patients).

Conclusion: Severity of osteoarthritis has a negative impact on measurements of different radiographic parameters. Therefore - in our opinion - epidemiological studies on prearthrotic deformities should only be performed in healthy adults with no signs of osteoarthritic changes.

Keywords: Radiographic Signs, Impingement, Hip, Dysplasia, Osteoarthritis

\footnotetext{
* Correspondence: Ingmarlpach@gmx.de

'Department of Orthopaedic Surgery, University Hospital of Tuebingen,

Hoppe-Seyler-Straße 3, 72074 Tuebingen, Germany

${ }^{2}$ Department of Orthopedic Surgery, Hospital of Ingolstadt,

Krumenauerstraße 25, 85021 Ingolstadt, Germany

Full list of author information is available at the end of the article
} 


\section{Background}

During the last years, terms like acetabular retroversion, excessive overcoverage, and abnormal head-neck-junction with the so called "pistol-grip-deformity" [1-4] has been added to the classical description of hip dysplasia with a lateral CEA-angle of less then $25^{\circ}$ and a roof obliquity angle of more than $10^{\circ}$ [5]. These anatomical changes could lead to a femoroacetabular impingement (FAI). Two kinds of FAI have been described. In Cam impingement a repetitive contact between an abnormal head-neckjunction and the acetabular rim causes cartilage damage in the anterosuperior area of the acetabulum. In Pincer impingement a direct contact between the femoral neck and a local/generalized overcovered acetabulum leads also to repetitive damage of the cartilage at the acetabular rim [6-16].

Both kinds of FAI has been indentified as a main reason for hip pain and progressive degenerative changes leading to early osteoarthritis of the hip [1-4,6,7].

The diagnosis of FAI should be based on detailed physical examination and appropriate imaging studies. A lot of radiographic criteria on pelvic views have been established to detect classical dysplasia and FAI [17-21]. The head-ratio has already described as reliable for the detection of "pistol-grip-deformity" [7,8,22]. It has also been shown that radiographic FAI findings are very common in a population of healthy young adults [23].

Goodman et al. have shown that "pistol-grip-deformity" is due to a three-dimensional structural abnormality with no change in severity with age [24].

According to Kellgren and Lawrence [25] progressive degenerative changes lead to osteophytes, narrowing of the joint space, and deformity of the bone ends. These changes may have a negative impact on radiographic parameters. The present study was initiated to assess the influence of severity of osteoarthritis on radiographic parameters.

\section{Methods}

Ethical approval has been received by the ethic committee of Tübingen (025/2014R). We analysed our data bank for all pelvic-views which has been performed in our institution in the period between $1^{\text {st }}$ January 2006 and $31^{\text {st }}$ December 2011.

To exclude the negative influence of pelvic tilt and rotation on radiographic parameters, only standardized pelvic radiographs were included in this study. The distance between the tip of the coccyx and the middle of the symphysis was $32 \mathrm{~mm}$ for men and $47 \mathrm{~mm}$ for women and the teardrop sign appeared symmetrical [1].

The pelvic-views were measured for head-ratio, CEangle, roof obliquity, extrusion-index, depth-to-width ratio, CCD-angle, sharp's angle [8,17-20,22,26]. In cases with the presents of a THA, fracture or Dysplasia Crowne II/IV on one side, only the other was measured.

To evaluate the severity of osteoarthritis of the hip the classification by Kellgren and Lawrence was used [25].

\section{Statistical analysis}

Statistical analyses were conducted with the use of IBM SPSS Statistics 21 and R software, version 3.0.0 ( $\mathrm{R}$ Core Team).

In order to account for repeated measurements of both hips on patient level, analysis was conducted separately for left and right hips or using summarized values for both sides (i.e. mean or maximum values of both hips).

When analyzing the influence of age on severity of osteoarthritis different radiographic parameters, left and right hip were analyzed separately.

When analyzing the influence of severity of osteoarthritis on the different radiographic parameters, the most severe hip and corresponding measurements or in case of equal severity on both sides, averaged measurements over both hips were considered for each patient.

Categorical variables are presented as frequencies, percentages, and continuous variables as means and standard deviations, or medians and interquartile ranges (Boxplots) for variables with skewed distributions.

Associations between age and radiographic parameters or severity of osteoarthritis were assessed by Spearman's $(\rho)$ or Kendall's $(\tau)$ rank correlation coefficient, respectively. Group comparisons based on severity of osteoarthritis of continuous measurements were conducted using either the one-way analysis of variances (ANOVA) or the Kruskall-Wallis test, as appropriate.

All reported P values are two-tailed, with a $\mathrm{P}$ value of 0.05 indicating statistical significance and have not been adjusted for multiple testing.

\section{Results}

The pelvic radiographs of 1614 Patients were included into this study. In 1052 of all cases both sides were measured in 562 cases only the left $(n=311)$ or right side $(n=251)$ were measured for radiographic signs of FAI and dysplasia.

Table 1 Measurement values for the different radiographic parameters of both hips

\begin{tabular}{|c|c|c|c|c|c|c|c|}
\hline $\mathrm{n}=$ & $\begin{array}{l}\text { Sharps-angle } \\
\text { (in degree) }\end{array}$ & Head-ratio & $\begin{array}{l}\text { CE-angle } \\
\text { (in degree) }\end{array}$ & $\begin{array}{l}\text { Roof obliquity } \\
\text { (in degree) }\end{array}$ & $\begin{array}{l}\text { Extrusion-index } \\
\text { (in \%) }\end{array}$ & $\begin{array}{l}\text { Depth-to-width } \\
\text { ratio (in \%) }\end{array}$ & $\begin{array}{l}\text { CCD-angle } \\
\text { (in degree) }\end{array}$ \\
\hline 1614 & $\begin{array}{c}9.75^{\circ} \pm 5.40^{\circ} \\
\left(1^{\circ}-34^{\circ}\right)\end{array}$ & $\begin{array}{c}1.13 \pm 0.26 \\
(0.76-2.40)\end{array}$ & $\begin{array}{c}40.05^{\circ} \pm 10.13^{\circ} \\
\left(0^{\circ}-70^{\circ}\right)\end{array}$ & $\begin{array}{c}35.27 \pm 4.96 \\
(10-55)\end{array}$ & $\begin{array}{l}12.99 \pm 9.21 \\
(6.20-95.2)\end{array}$ & $\begin{array}{l}59.30 \pm 8.90 \\
(6.30-100)\end{array}$ & $\begin{array}{c}127.68^{\circ} \pm 7.22^{\circ} \\
\left(123^{\circ}-162^{\circ}\right)\end{array}$ \\
\hline
\end{tabular}

The results are presented as means and standard deviations (Minimum - Maximum). 


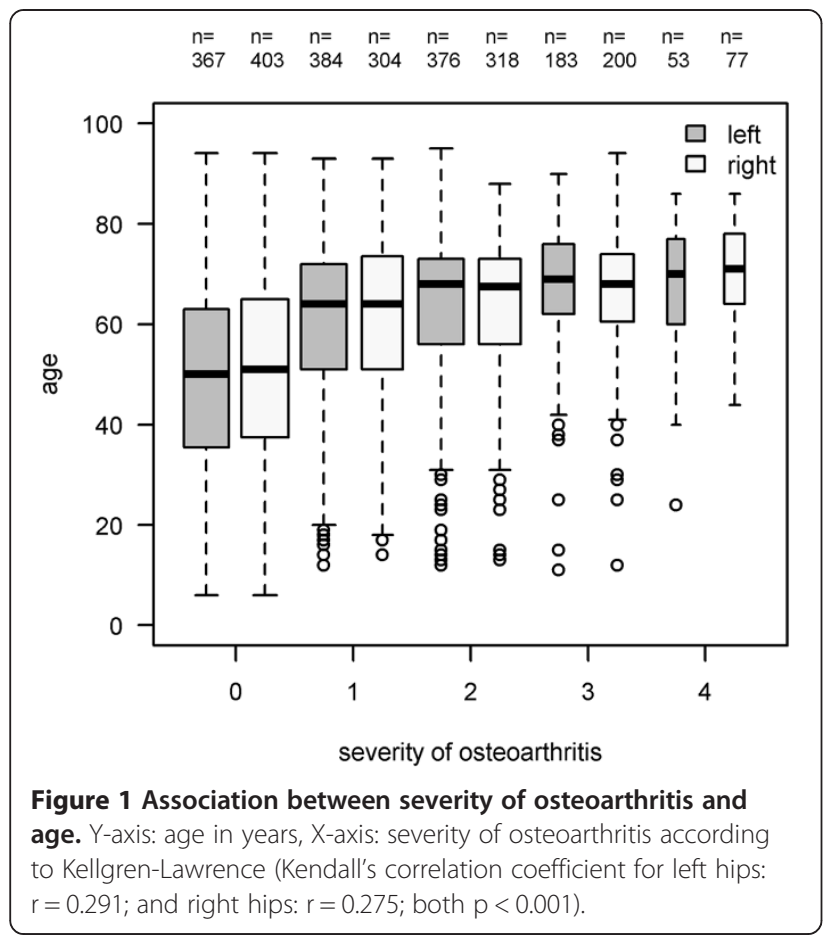

The mean age of all patients was 60.2 years \pm 17.1 . $44.4 \%$ of all patients were male, $55.6 \%$ were female.

$366(22.7 \%)$ patients presented no sign of osteoarthritis, $367(22.7 \%)$ patients presented $\mathrm{I}^{\circ}$ osteoarthritis, 460 (28.5\%) patients presented $\mathrm{II}^{\circ}$ osteoarthritis, 307 (19\%) $\mathrm{III}^{\circ}$ osteoarthritis and $114(7.1 \%)$ patients presented $\mathrm{IV}^{\circ}$ osteoarthritis of the hip.

The mean values of all different radiographic parameters are demonstrated in Table 1. There was a weak association between age and the severity of osteoarthritis of the hips (left: $\tau=0.291$; right: $\tau=0.275$; both $\mathrm{P}<0.001$ ) with higher osteoarthritis levels observable for elderly patients (Figure 1).

The correlation between age and head-ratio, CE-angle, roof obliquity, extrusion-index, depth-to-width ratio, CCDangle, sharp's angle is demonstrated in Figures 2 and 3. Weak monotone associations were also observed between age and mean CE-angle $(\rho=0.334) \quad(p<0.001)$, mean sharps angle $(p=-0.299)(p<0.001)$, mean extrusion-index $(\rho=-0.218)(p<0.001)$, and mean CCD-angle $(\rho=-0.205)$ $(\mathrm{p}<0.001)$. On the other hand no correlations were seen between age and depth-to-width ratio $(\rho=0.033)$ $(\mathrm{p}<0.181)$, roof obliquity $(\rho=0.133)(\mathrm{p}<0.001)$ and headratio $(\rho=0.135)(p<0.001)$. These results imply that age

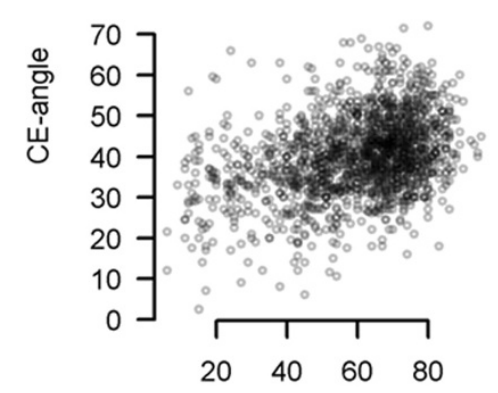

a

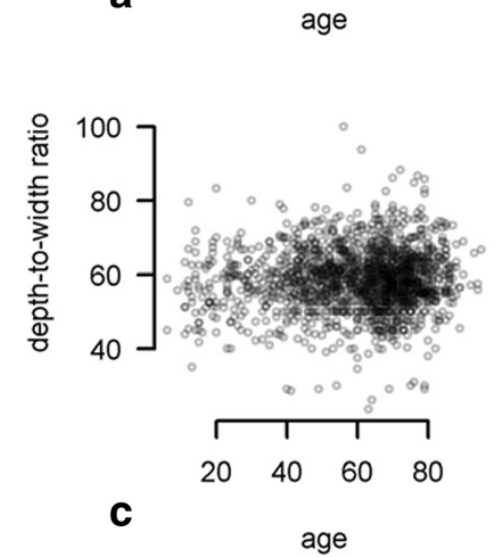

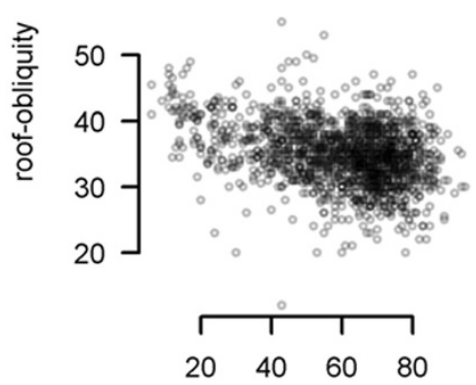

b

age

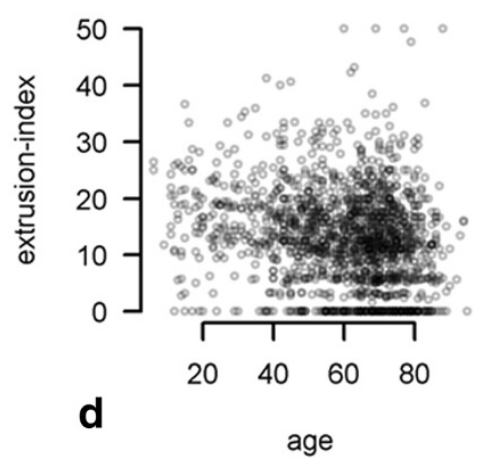

Figure 2 Correlation between CE-angle, roof-obliquity, depth-to-width-ratio, extrusion-index and age. a: Correlation between age and CE-angle. X-axis: age in years, Y-axis: CE-angle in degree. There was a weak monotone correlation between age and CE-angle ( $\rho=0.334)$. b: Correlation between age and roof-obiquity. X-axis: age in years, $Y$-axis: roof obliquity in degree. There no correlation between age and roof obliquity $(\rho=-0.133)$. c: Correlation between age and depth-to-width-ratio. X-axis: age in years, Y-axis: depth-to-width-ratio in \%. There was no correlation between age and depth-to-width-ratio $(\rho=0.033)$ d: Correlation between age and extrusion-index. X-axis: age in years, $Y$-axis: extrusion-index in \%. There was weak negative correlation between age and extrusion-index $(\rho=-0.218)$. 


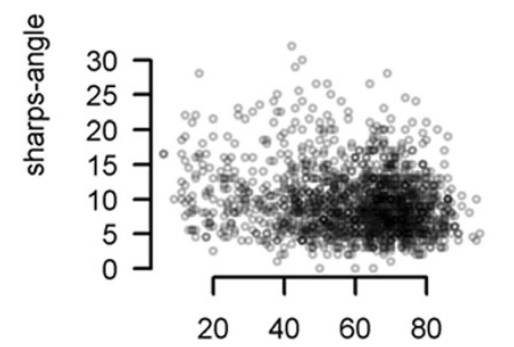

a

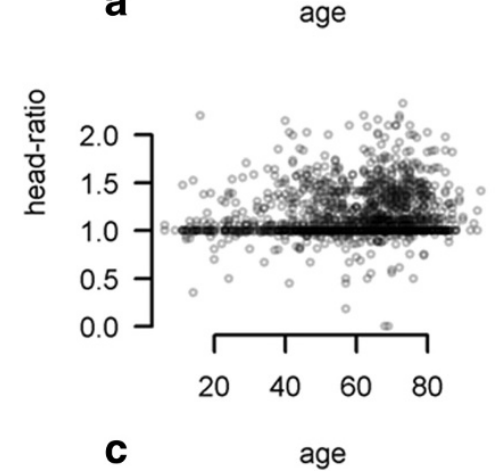

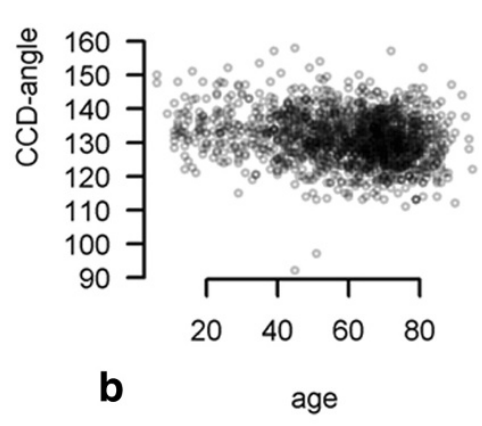

age

Figure 3 Correlation between sharps-angle, CCD-angle, head-ratio and age. a: Correlation between age and sharps-angle. $X$-axis: age in years, Y-axis: sharps-angle in degree. There was weak negative correlation between age and sharps-angle $(\rho=-0.299) \mathbf{b}$ : Correlation between age and CCD-angle. X-axis: age in years, Y-axis: CCD-angle in degree. There was weak negative correlation between age and CCD-angle $(\rho=-0.205)$ c: Correlation between age and head-ratio. X-axis: age in years, $Y$-axis: head-ratio There was no correlation between age and head-ratio $(\rho=0.135)$

has only a weak or no impact on the different radiographic parameters for FAI and dysplasia. One-way ANOVA revealed statistical significant differences between patient groups based on severity (Kellgren-Lawrence $1^{\circ}-4^{\circ}$ ) of osteoarthritis for the following measurements: CE-angle $(\mathrm{p}<0.001)$, sharps-angle $(\mathrm{p}<0.001)$, Extrusion-index $(\mathrm{p}<0.001)$, and CCD-angle $(\mathrm{p}<0.001)$. No statistical significant difference between patient groups based on severity (Kellgren-Lawrence $1^{\circ}-4^{\circ}$ ) and depth-to-width ratio was seen $(p=0.535)$. Assuming a skewed distribution of head-ratio and roof-obliquity measurements, the nonparametric Kruskall-Wallis-test revealed a statistical significant difference between osteoarthritis groups headratio $(\mathrm{P}<0.001)$ but none for roof-obliquity (Figure 4 ) $(P=0.18)$. These results imply that there is an association between the different radiographic parameters (excluded roof-obliquity and depth-to-width ratio) and the severity of osteoarthritis of the hip.

\section{Discussion}

During the last years a lot of studies have shown changes in the acetabular geometry and the head neck region as a main reason for an early osteoarthritis of the hip. Terms like femoroacetabular impingement have become more and more important in the explanation for hip pain and the early development of OA. These morphologic changes in the acetabular geometry such as an excessive overcoverage or an acetabular retroversion or changes in the head-neck-region lead to the so-called Pincer- or Cam-impingement [6-18].

However, the "classic" definition of hip-dysplasia with an undercoverage of the femoral head (reduced CE-angle) or a steep acetabular roof (increased roof obliquity) is still playing an important role in the indication of total hip arthroplasty in young adults [26-30].

While watching different epidemiological studies, an abnormal hip morphology with acetabular dysplasia has been reported in about $51-80 \%$ of all cases with OA of the hip [23]. Including radiographic findings for an excessive overcoverage of the femoral head, acetabular retroversion or an abnormal head-neck-junction, as a dysplastic change, hip-dysplasia was seen in nearly $97 \%$ of all patients [26].

The prevalence of acetabular dysplasia has been reported to be about $3.8 \%$ in the British population [28] and $4.5 \%$ in Chinese men [29]. An abnormal head-neckjunction seems to be present in about $40 \%-50 \%$ of all hips with OA $[26,30]$. A recent study has shown a high prevalence of radiographic finding for FAI in a cohort of 2081 healthy adults. The prevalence of CAM-impingement was up to $40 \%$, the prevalence of Pincer-impingement up to $50 \%$ [23].

The present study was performed to assess the impact of severity of osteoarthritis on different radiographic 


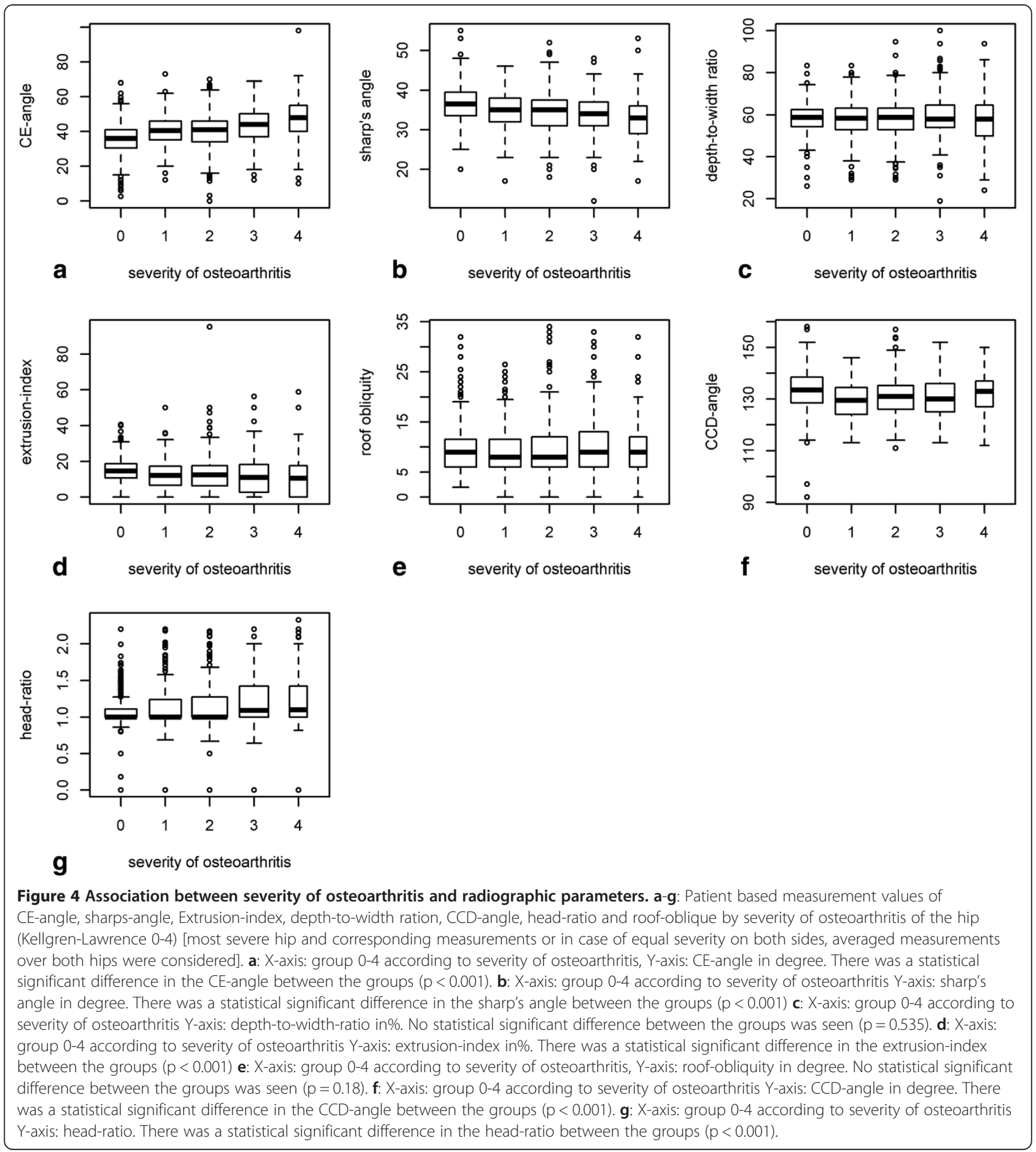

measurement values. We were able to show that degenerative changes has an negative impact on radiographic parameters for FAI and hip dysplasia. To our knowledge this was the first study focusing on this topic.

The posterior head tilt in osteoarthritic hips has been discussed as being an acquired deformity created by the formation of osteophytes [8]. The present study support these findings, as the head-ratio demonstrated an increase with the severity of osteoarthritis. On the other hand it was shown that this deformity did not change with age and therefore it could be seen as a prearthrotic deformity and not as secondary to degeneration [24].

We not several limitations in this study. A testing on intra- and interobserver reliability hasn't be performed in this study, but previous studies already focussed on this topic [31]. Clohisy et al. [32] and Gosving et al. [33] 
reported about poor results for inter- and intra-observer reliability of measurements of radiographic signs for acetabular dysplasia, head-neck offset and pelvic tilt. Other studies were able to show a high inter- and intraobserver reliability for different radiographic parameters by using the Balnd-Altman-method [26,31,34,35]. The discrepancy between these studies could be explained by the using of different statistical methods. The kappa-coefficient by Cohen [34] is the first choice for testing inter- and intraobserver quality of categorical variables, it should not be used for data on a continuous level [34,35]. Correlation coefficients for testing reliability between two observers should not be used at all [34]. Therefore the BlandAltman-method is a better choice for assessing agreement of continuous data $[34,35]$.

Nevertheless the inter- and intrabserver quality of radiographic findings in the diagnostic of dysplasia, FAI and excessive overcoverage is one of the main problem in the clinical routine. Therefore the use of a threedimensional imaging might be helpful in unclear cases.

\section{Conclusion}

There seems to be a negative impact of severity of osteoarthritis on different radiographic parameters for the detection of femoroacetabular impingement and hip dysplasia. Therefore - in our opinion - epidemiological studies on prearthrotic deformities and radiographic paramters for FAI and hip dysplasia should only be performed in adults with no signs of osteoarthritic changes.

\section{Abbreviations}

CE-angle: Centre-edge-angle; CCD-angle: Caput-collum-diaphysis-angle: FAl: Femoroacetabular impingement; OA: Osteoarthritis; THA: Total hip arthroplasty.

\section{Competing interests}

The authors declare that they have no competing interests.

\section{Authors' contributions}

II: Drafting the manuscript IR: statistical analysis SS: graphical design, recruiting $x$-rays EB: performing measurements RS: controlling accuracy of measurements and quality of $x$-rays FM: Study design. All authors read and approved the final manuscript.

\section{Author details}

${ }^{1}$ Department of Orthopaedic Surgery, University Hospital of Tuebingen, Hoppe-Seyler-Straße 3, 72074 Tuebingen, Germany. ${ }^{2}$ Department of Orthopedic Surgery, Hospital of Ingolstadt, Krumenauerstraße 25, 85021 Ingolstadt, Germany. ${ }^{3}$ Department of Medical Statistics and Epidemiology, Technische Universität München, Ismaninger Str. 22, Munich 81675, Germany. ${ }^{4}$ Department of Radiology, University Hospital of Tuebingen, Hoppe-Seyler-Straße 3, 72074 Tuebingen, Germany.

Received: 10 January 2014 Accepted: 30 April 2014

Published: 8 May 2014

\section{References}

1. Beall DP, Sweet CF, Martin HD: Imaging findings of femoroacetabular impingement syndrome. Skeletal Radiol 2005, 34:91-701.

2. James SL, Ali K, Malara F, Young D, O'Donnell J, Connell DA: MRI findings of femoroacetabular impingement. AJR 2006, 187:1412-1419.
3. Tannast M, Kubiak-Langer M, Langlotz F, Puls M, Murphy SB, Siebenrock KA: Non invasive threedimensional assessment of femoroacetabular impingement. J Orthop Res 2007, 25:122-131.

4. Siebenrock KA, Schoeninger R, Ganz R: Anterior femoro-acetabular impingement due to acetabular retroversion: treatment with periacetabular osteotomy. J Bone Joint Surg Am 2003, 5(A):278-286.

5. Miller MD: Review of Orthopaedics $5^{\text {th }}$ edition. Philadelphia: Saunders Elsevier; 2008.

6. Ganz R, Parvizi J, Beck M, Leunig M, Nötzli H, Siebenrock KA: Femoroacetabular impingement: a cause for osteoarthritis of the hip. Clin Orthop Relat Res 2003, 417:112-120.

7. Nötzli HP, Wyss TF, Stoecklin CH, Schmid MR, Treiber K, Hodler J: The contour of the femoral head-neck junction as a predictor for the risk of anterior impingement. J Bone Joint Surg (Br) 2002, 84:556-560.

8. Murray RO: The aetiology of primary osteoarthritis of the hip. Br J Radiol 1965, 38:810-824.

9. Jäger $M$, Wild $A$, Westhoff $B$ : Femoroacetabular impingement caused by a femoral osseous head-neck bump deformity: clinical, radiological, and experimental results. J Orthop Sci 2004, 9:256-263.

10. Koegh MJ, Batt ME: A review of femoroacetabular impingement in athletes. Sports Med 2008, 38:863-878.

11. Stafford G, Witt J: The anatomy, diagnosis and pathology of femoroacetabular impingement. Br J Hosp Med 2009, 70:72-77.

12. Anda S, Terjesen T, Kvistad KA, Svenningsen S: Acetabular angles and femoral anteversion in dysplastic hips in adults: CT-investigation. J Comput Assist Tomogr 1991, 15(1):115-120.

13. Anderson LA, Peters CL, Park BB, Stoddard GJ, Erickson JA, Crim JR: Acetabular cartilage delamination in femoroacetabular impingement. Risk factors and Magnetic Resonance imaging diagnosis. J Bone Joint Surg Am 2009, 91:305-313.

14. Fadul DA, Carrino JA: Imaging of femoroacetabular impingement. J Bone Joint Surg Am 2009, 91:138-143.

15. Murphy SB, Ganz R, Müller ME: The prognosis in untreated dysplasia of the hip. A study of radiographic factors that predict the outcome. J Bone Joint Surg Am 1995, 77(7):985-989.

16. Laude F, Boyer T, Nogier A: Anterior femoroacetabular impingement. Joint Bone Spine 2007, 74:127-132.

17. Lequesne M: Coxometry measurement of the basic angles of the adult radiographic hip by a combined protractor. Rev Rhum Mal Osteoartic 1963, 30:479-485.

18. Tannast M, Siebenrock KA, Anderson SE: Femoroacetabular Impingement: radiographic diagnosis - what the radiologist should know. Am J Roentgenol 2007, 188(6):1540-1552.

19. Steppacher SD, Tannast M, Werlen S, Siebenrock KA: Femoral morphology differs between deficient and excessive acetabular coverage. Clin Orthop Relat Res 2008, 466(4):782-790.

20. Tönnis $D$, Heinecke A: Acetabular and femoral anteversion: relationship with osteoarthritis of the hip. J Bone Joint Surg Am 1999, 81(12):1747-1770.

21. Wiberg G: Studies on dysplastic acetabula and congenital subluxation of the hip joint: With special reference to the complications of osteoarthritis. Acta Chir Scan 1939, 58:7-38.

22. Ipach I, Mittag F, Sachsenmaier S, Heinrich P, Kluba T: A new classification for "pistol grip deformity"- correlation between the severity of the deformity and the grade of osteoarthritis of the hip. Fortschr Röntgenstrahl 2010, 183(4):365-371.

23. Laborie LB, Lehmann TG, Engeæter I, Eastwood DM, Engeæter LB, Rosendahl K: Prevalence or radiographic findings thought to be associated with femoroacetabular impingement in a population-based cohort of 2081 healthy young adults. Radiology 2011, 260:494-502.

24. Goodman DA, Feighan JE, Smith AD, Latimer B, Buly RL, Cooperman DR: Subclinical slipped capital femoral epiphysis. Relationship to osteoarthrosis of the hip. J Bone Joint Surg Am 1997, 79(10):1489-1497.

25. Kellgren JH, Lawrence JS: Radiological assessment of osteo-arthrosis. Ann Rheum Dis 1957, 16:494-502.

26. Ipach I, Mittag F, Syha R, Kunze B, Wolf P, Kluba T: Indications for total hip arthroplasty in young adults - idiopathic osteoarthritis seems to be overestimated. Röfo 2012, 184(3):239-247.

27. Harris WH: Etiology of osteoarthritis of the hip. Clin Orthop 1986, 213:20-33.

28. Cooperman DR, Wallensten R, Stulberg SD: Post-reduction avascular necrosis in congenital dislocation of the hip. J Bone Joint Surg Am 1980, 62(2):247-258. 
29. Lau EM, Lin F, Lam D, Silman A, Croft P: Hip osteoarthritis and dysplasia in Chinese men. Ann Rheum Dis 1995, 54(12):965-969.

30. Stulberg SD, Cordell LD, MacEwen GD: Unrecognized childhood hip disease: a major cause of idiopathic osteoarthritis of the hip. In The Hip Procs Third Open Scientific Meeting of the Hip Society St Louis. Edited by Amstutz HC. St. Louis: C V Mosby; 2010:212-218.

31. Ipach I, Arlt EM, Mittag F, Kunze B, Wolf P, Kluba T: A classification-system improves the intra- and interobserver reliability of radiographic diagnosis of "pistol-grip-deformity". Hip Int 2011, 21(6):732-739.

32. Clohisy JC, Carlisle JC, Trousdale R, Kim YJ, Beaule PE, Morgan P, Steger-May K, Schoenecker PL, Millis M: Radiographic evaluation of the hip has limited reliability. Clin Orthop Relat Res 2009, 467(3):666-675.

33. Gosvig KK, Jacobsen S, Sonne-Holm S, Palm H, Troelsen A: Prevalence of malformations of the hip joint and their relationship to sex, groin pain, and risk of osteoarthritis: a population-based survey. J Bone Joint Surg Am 2010, 92(5):1162-1169.

34. Bland JM, Altman DG: Measuring agreement in method comparison studies. Stat Methods Med Res 1999, 8:135-160.

35. Bland JM, Altman DG: A note on the use of the intracalss correlation coefficient in the evaluation of agreement between two methods of measurement. Comput Biol Med 1990, 20:337-340.

doi:10.1186/1471-2474-15-150

Cite this article as: Ipach et al:: Radiographic signs for detection of femoroacetabular impingement and hip dysplasia should be carefully used in patients with osteoarthritis of the hip. BMC Musculoskeletal Disorders 2014 15:150

\section{Submit your next manuscript to BioMed Central and take full advantage of:}

- Convenient online submission

- Thorough peer review

- No space constraints or color figure charges

- Immediate publication on acceptance

- Inclusion in PubMed, CAS, Scopus and Google Scholar

- Research which is freely available for redistribution 